\title{
Self-prescription of Paracetamol by Undergraduate Students in BP Koirala Institution of Health Sciences
}

\author{
Ajay Kumar Yadav, ${ }^{1}$ Bijendra Kumar Rai, ${ }^{1}$ Shyam Sundar Budhathoki, ${ }^{2}$ Anup Ghimire, ${ }^{2}$ Shree Ram Shrestha, \\ Gyanendra Bahadur Malla' \\ 'Department of General Practice and Emergency Medicine, B P Koirala Institute of Health Sciences, Dharan, Nepal, ${ }^{2}$ School \\ of Public Health \& Community Medicine, B P Koirala Institute of Health Sciences, Dharan, Nepal.
}

\section{ABSTRACT}

Introduction: Self-prescription of medicines are common especially in low income countries. Paracetamol is a common medicine that is self-prescribed also among university students. Incorrect use of paracetamol can lead to ill effects on health including liver failure. There is scarce evidence of the use of paracetamol by self-medication in Nepal. The objective of this study is to evaluate the paracetamol use by self-prescription among the undergraduate students of BPKIHS.

Methods: A cross-sectional study was conducted among 570 undergraduate students of BPKIHS from February 2016 till July 2016. Pretested semi-structured, self-administered questionnaire was used to collect information regarding socio-demographic characteristics, paracetamol use and perception regarding paracetamol use. Systematic random sampling was done from a list of all medical dental and nursing students to select the study sample.

Results: Most (86\%) students are in the category of 20-24 years. Female students are slightly more than male. Majority of the students are from Nepal. More than half of the students are from medical stream. Self-prescription of paracetamol is seen among $90.1 \%$ of the students in our study. Correct dose of paracetamol was mentioned by less than half $(49.3 \%)$ of the students. Self-prescription of paracetamol is considered beneficial by all participants of this study.

Conclusions: Self-prescription of paracetamol by health sciences students of B P Koirala Institute of Health Sciences is high, while the knowledge of correct dose of paracetamol for adults is low. There is a need to further explore this gap and possibly conduct further studies for other medicines as well.

Keywords: paracetamol; self-prescription; health sciences students; undergraduate students.

\section{INTRODUCTION}

Paracetamol is used for pain and fever. Paracetamol interacts with some drugs and there are some reports of blood disorders as thrombocytopenia, leucopoenia and neutropenia. High dose of paracetamol can cause liver damage and renal tubular necrosis. ${ }^{1}$ Poor knowledge dose and easy availability of has contributed to increase in morbidity. ${ }^{2}$

Self-medication is common in low income countries. ${ }^{3-6}$
Paracetamol self-prescriptions is more common among university students. ${ }^{7}$ Self-medication refers to the selection and use of medicines by individuals to treat self-recognized illnesses or symptoms. ${ }^{8}$ Paracetamol

Correspondence: Dr. Ajay Kumar Yadav, Department of General Practice and Emergency Medicine, BP Koirala Institute of Health Sciences, Dharan, Nepal. Email: ajay.yadav@bpkihs.edu, Phone: +977. 9841232328 . 
is commonly used also for self-poisoning. ${ }^{2,9-11}$ Selfmedication is one component of self-care, more organised and balanced approach may be necessary for self-medication to be beneficial to health of the people. ${ }^{12}$

Around the world, studies show $38.5 \%$ of students $^{7}$ to $77 \%$ students ${ }^{13}$ practiced self-medication with paracetamol. ${ }^{14}$

With limited literatures found about paracetamol consumption, this study explores the paracetamol use by self-prescription among the undergraduate students of BPKIHS.

\section{METHODS}

A cross-sectional study was conducted among 570 undergraduate students of BPKIHS from February 2016 till July 2016. A pretested semi-structured self-administered questionnaire was used to collect information regarding socio-demographic characteristics, paracetamol use and perception regarding paracetamol use among the undergraduate students. All current undergraduate students of BPKIHS willing to participate in the study were included. Elective students, interns, short course participants and foreign elective students were excluded in this study.

Systematic random sampling was done from a list of all medical dental and nursing students to select the study sample. We obtained the required sample size using the prevalence of self-prescription of paracetamol among undergraduate students in Srilanka ${ }^{13}$ as $77 \%$ as; prevalence $(p)=77 \%$, compliment of prevalence $(q)=$ $23 \%$, allowable error $(\mathrm{I})=5 \%$ of $77 \%=3.85$; sample size $=4 \times(\mathrm{pq}) / /^{2}=4 \times(77 \times 23) / 3.85^{2}=479$ students. We also added $20 \%$ for non-response which gave us the final sample size as 575 students.

Data are presented as frequency, percentage and mean. Chi-square test was used to test the association of the categorical variables at $95 \%$ Confidence Interval and $5 \%$ level of significance. The study was conducted after approval from the Institutional Review Committee (IRC) of B P Koirala Institute of Health Sciences, Dharan. Informed verbal consent was taken and the questionnaire was provided for self-administration. Data regarding personal identification was not taken from the students.

\section{RESULTS}

A total of 570 out of 575 students approached for this study responded to the questionnaire giving a response rate of more than $99 \%$. Most $(86 \%)$ students are in the category of 20-24 years. Female students are slightly more than male. Majority of the students are from Nepal. More than half of the students are from medical stream. The socio-demographic characteristics of the respondents can be found in table 1 .

\begin{tabular}{|c|c|c|}
\hline Characteristics & & n (\%) \\
\hline \multirow{3}{*}{ Age } & upto 19 years & $59(10.4 \%)$ \\
\hline & 20-24 years & $490(86.0 \%)$ \\
\hline & 25 and above & $21(3.7 \%)$ \\
\hline \multirow{2}{*}{ Sex } & Male & $275(48.2 \%)$ \\
\hline & Female & $295(51.8 \%)$ \\
\hline \multirow{2}{*}{ Country } & Nepal & 507 (88.9\%) \\
\hline & India & $63(11.1 \%)$ \\
\hline \multirow{3}{*}{ Stream } & Medical Students & $330(57.9 \%)$ \\
\hline & Dental Students & $140(24.6 \%)$ \\
\hline & Nursing Students & $100(17.5 \%)$ \\
\hline \multirow{4}{*}{ Year of Study } & Year 1 & $152(26.7 \%)$ \\
\hline & Year 2 & $153(26.8 \%)$ \\
\hline & Year 3 & $132(23.2 \%)$ \\
\hline & Year 4 & $133(23.3 \%)$ \\
\hline \multirow{2}{*}{$\begin{array}{l}\text { Involved in } \\
\text { Sports }\end{array}$} & Yes & $327(57.4 \%)$ \\
\hline & No & $243(42.6 \%)$ \\
\hline Total & & $570(100 \%)$ \\
\hline
\end{tabular}

Correct dose of paracetamol was mentioned by less than half $(49.3 \%)$ of the students. Only less than $10 \%$ of the students took paracetamol with doctor's prescription. More than $80 \%$ of the students got paracetamol from the local pharmacy shop. 


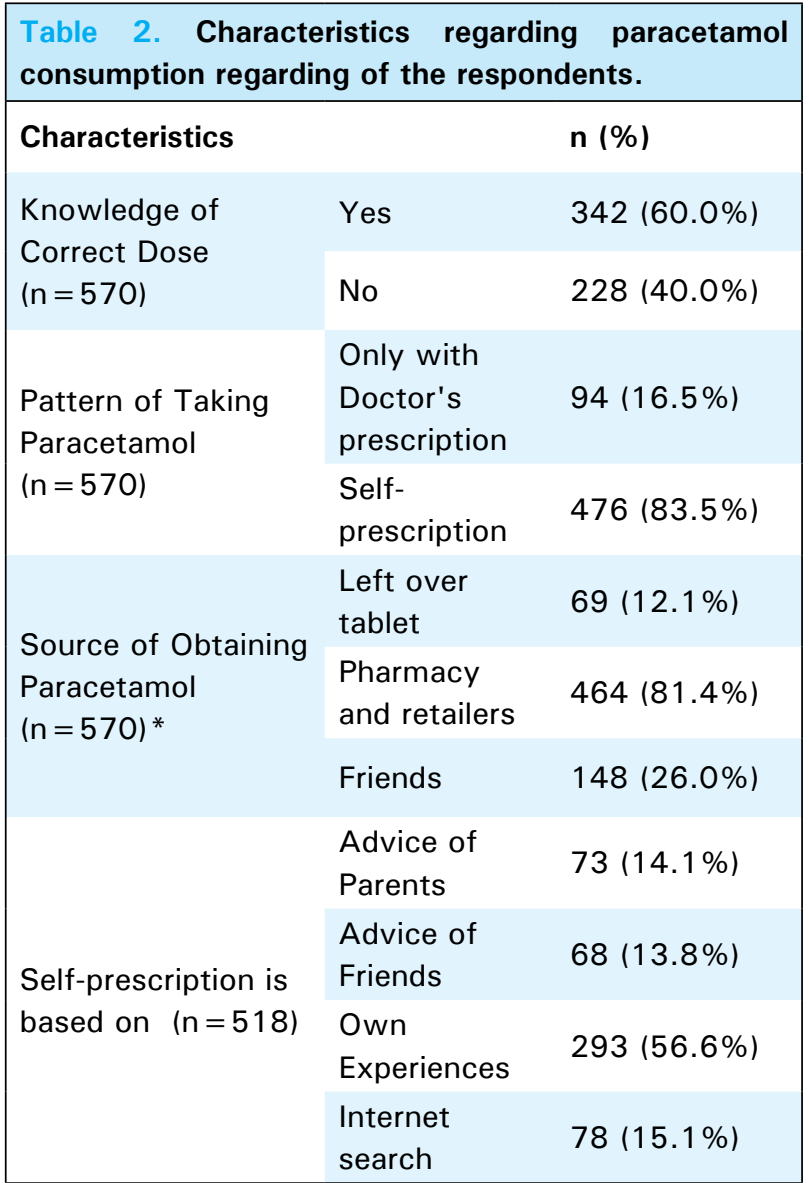

There was equal proportion of student who thought prescription was not necessary for paracetamol, avoiding time wasting and having good knowledge as reasons for using paracetamol without prescription.

The knowledge of the correct dose of paracetamol increased with the year of the study among the student. The self-prescription also increased with the year of the study. The association of knowledge of the correct dose and the self-prescription with the year of the study was found to be highly significant.

\begin{tabular}{|c|c|c|}
\hline $\begin{array}{l}\text { Table 3. Reaso } \\
\text { prescription and } \\
\text { use. }\end{array}$ & $\begin{array}{l}\text { is for paracetamol } \\
\text { perception regardin }\end{array}$ & $\begin{array}{l}\text { use without } \\
\text { paracetamol }\end{array}$ \\
\hline Characteristics & & Frequency \\
\hline Reason for using & $\begin{array}{l}\text { Prescription Not } \\
\text { Necessary }\end{array}$ & $173(33.4 \%)$ \\
\hline $\begin{array}{l}\text { Paracetamol } \\
\text { without } \\
\text { prescription }\end{array}$ & Avoid time wasting & $174(33.6 \%)$ \\
\hline$(n=518)$ & $\begin{array}{l}\text { I have good } \\
\text { Knowledge }\end{array}$ & $171(33.0 \%)$ \\
\hline & Strongly disagree & $25(4.4 \%)$ \\
\hline In practice, it & Disagree & $184(32.3 \%)$ \\
\hline $\begin{array}{l}\text { use paracetamol } \\
\text { should without }\end{array}$ & No Idea & $92(16.1 \%)$ \\
\hline$(n=570)$ & Agree & $239(41.9 \%)$ \\
\hline & Strongly Agree & $30(5.2 \%)$ \\
\hline & $\begin{array}{l}\text { PCM is OTC } \\
\text { drug and can be } \\
\text { taken without } \\
\text { prescription }\end{array}$ & $225(39.5 \%)$ \\
\hline $\begin{array}{l}\text { Overall Concept } \\
\text { of using }\end{array}$ & $\begin{array}{l}\text { I have experiences } \\
\text { and can advise } \\
\text { others }\end{array}$ & $171(30.0 \%)$ \\
\hline $\begin{array}{l}\text { Paracetamol } \\
(n=570)\end{array}$ & $\begin{array}{l}\text { Self-prescription } \\
\text { is not harmful for } \\
\text { PCM }\end{array}$ & $117(20.5 \%)$ \\
\hline & $\begin{array}{l}\text { Self-prescription } \\
\text { is time saving and } \\
\text { cost effective }\end{array}$ & $57(10.0 \%)$ \\
\hline
\end{tabular}

Table 4. Association between year of study with Knowledge of dose and self-prescription of paracetamol $(\mathbf{n}=\mathbf{5 7 0}$ ).

\begin{tabular}{|c|c|c|c|c|c|c|}
\hline \multirow{2}{*}{$\begin{array}{l}\text { Year of } \\
\text { study }\end{array}$} & \multicolumn{2}{|c|}{ Know ledge of correct dose } & \multirow[t]{2}{*}{$p$-value } & \multicolumn{2}{|c|}{ Self-Prescription } & \multirow{2}{*}{$p$-value } \\
\hline & Yes & No & & Yes & No & \\
\hline Year 1 & $46(30.3 \%)$ & $106(69.7 \%)$ & \multirow{4}{*}{0.000} & $114(75.0 \%)$ & $38(25.0 \%)$ & \multirow{4}{*}{0.000} \\
\hline Year 2 & $92(60.1 \%)$ & $61(39.9 \%)$ & & $124(81.0 \%)$ & $29(19.0 \%)$ & \\
\hline Year 3 & $94(71.2 \%)$ & $38(28.8 \%)$ & & $114(86.4 \%)$ & $18(13.6 \%)$ & \\
\hline Year 4 & $110(82.7 \%)$ & $23(17.3 \%)$ & & $124(93.2 \%)$ & $9(6.8 \%)$ & \\
\hline Total & $342(60.0 \%)$ & $228(40.0 \%)$ & & $476(83.5 \%)$ & $94(16.5 \%)$ & \\
\hline
\end{tabular}




\section{DISCUSSION}

Most undergraduate students in this study are in the age of 20-24 years. This is the common age group in undergraduate health sciences education in Nepal. This is similar in context of India as well. ${ }^{15}$ We have slight high proportion of female students as the nursing students are about a fifth of our study population and are all females. Nursing education exclusively for females in Nepal.

Studies have shown that self-prescription of drugs is seen among students of all disciplines and general population. ${ }^{6,13,16-18}$ Paracetamol is cited as the most common used analgesic drug. ${ }^{19}$ The prevalence of selfprescription of paracetamol in this study is $90.9 \%$. This figure is quite high. It is known that paracetamol is a common drug for self-prescription. However this is higher than other studies. This is in contrast to the finding that only a little over half of the students know the correct doses of paracetamol for adults. The self-prescription of paracetamol in India ${ }^{15} \operatorname{Iran}^{20}$ and Saudi Arabia $^{21}$ are also high $(78.6 \%, 76.6 \%$ \& $75.2 \%$ respectively), however the findings in our study is much lower than these study. As this is the first study in this university, further exploration in to the matter may provide more evidence on factors that may have led to the high self-prescription of paracetamol in this study. Study suggests the use of diaries to monitor the use of drugs without prescription among University students. ${ }^{9}$ A study cites easy availability of paracetamol as the most important factor for frequent use of paracetamol. ${ }^{22}$ This can be explored in our setting as well. While the self-prescription is seen high the knowledge of correct dose of paracetamol is low among the students in this study.

Pharmacy is the place to obtain paracetamol for most of the study participants. This is in line with findings from other studies. ${ }^{6}$ More than half of the respondents self-prescribe paracetamol based on their own personal experiences. This finding is similar to another study from Ethiopia among health sciences university students. ${ }^{12}$ A study from western Nepal cites non-availability of doctor as the most frequent reason for self-prescription. ${ }^{5}$
As the current study is done among health sciences university students who live inside the campus, the unavailability of doctor is not an issue in this study. We take this as a positive sign that students also use internet to check for information to decide for use of paracetamol. However this must be closely explored whether they are using authentic sources to decide and their ability to decide on the use by themselves. A similar proportion of students in India use internet to decide on self-prescription. ${ }^{6,15}$ The self-prescription among the students increased with the increase in the year of the study. This could be explained as they advanced in their health sciences courses, they gained more knowledge and became more confident to selfprescribe paracetamol. The knowledge of the correct dose was also seen to be more as the year of the student increased.

This study provides preliminary evidence on the selfprescription of paracetamol. Only less than half of the respondents agree that paracetamol should not be used with self-prescription. Students perceive that paracetamol can be taken without prescription safely and it saves time. Self-prescription of paracetamol is not considered harmful by health sciences student in other settings as well. ${ }^{13}$

\section{CONCLUSIONS}

There is high self-prescriptive use of paracetamol among health sciences students with a low knowledge of correct dose of paracetamol. The study provides preliminary evidences on the use of paracetamol of health sciences students in B P Koirala Institute of Health Sciences. Further studies on use of other medicines may also be started on the basis of this study. The high use of non-prescription needs to be carefully studies and relevant interventions may need to be designed.

\section{ACKNOWLEDGEMENTS}

We acknowledge BPKIHS for permitting this study. We express our gratitude to Dr Gopal Yadav and Dr Alok Kumar for supporting this study during data collection.

\section{REFERENCES}

1. National Health Service UK. British National Formulary. 54th ed. London: National Health Service; 2007. p. 224-5.

2. Gilbertson RJ, Harris E, Pandey SK, Kelly P, Myers W. Paracetamol use, availability, and knowledge of toxicity among British and American adolescents. Arch Dis Child. 1996;75:194-8.

3. Sclafer J, Slamet LS, de Visscher G. Appropriateness of self-medication: method development and testing in urban Indonesia. J Clin Pharm Ther. 1997;22(4):261-72.
4. Geissler PW, Nokes K, Prince RJ, Odhiambo RA, Aagaard-hansen J, Ouma JH. Children and medicines: self-treatment of common illnesses among Luo schoolchildren in western Kenya. Soc Sci Med. 2000;50:1771-83.

5. Shankar PR, Partha P, Shenoy N. Self-medication and non-doctor prescription practices in Pokhara valley, Western Nepal: a questionnaire-based study. BMC Fam Pract. 2002;3:17. 
6. Patel MM, Singh U, Sapre C, Salvi K, Shah A, Vasoya B. Self-medication practices among college students: a cross sectional study in Gujarat. Natl J Med Res. 2013;3(3):257-60.

7. Abay SM, Amelo W. Assessment of self-medication practices among Medical, Pharmacy, and Health Science students in Gondar University, Ethiopia. J Young Pharm. 2010;2(3):1-5.

8. Tahir MU, Shoaib N, Usman A, Sadiq S, Harris N-I-K. Prevalence of analgesic use amongst University students. PJMHS. 2011;195(4):775-7.

9. Acocella CM. Using diaries to assess nonprescription drug use among University students. J Drug Educ. 2005;35(4):267-74.

10. Lifshitz $M$, Gavrilov V. Deliberate self-poisoning in adolescents. Isr Med Assoc J. 2002;4:252-4.

11. McCabe SE, Teter CJ, Boyd CJ. Illicit use of prescription pain medication among college students. Drug Alcohol Depend. 2005;77:37-47.

12. Gutema GB, Gadisa DA, Kidanemariam ZA, Berhe DF, Berhe $\mathrm{AH}$, Hadera MG, et al. Self-medication practices among Health Sciences students: the case of Mekelle University. J Appl Pharm Sci. 2011;1(10):183-9.

13. Samarawickrama AAHS, Suraweera RK, Sivayoganathan C, Sakeena MHF. A study on Paracetamol consumption by undergraduate students in the Faculty of Allied Health Sciences, University of Peradeniya. Int J Sci Res Publ. 2014;4(6):1-6.

14. Puwar B. Self medication practice among adults of Ahmedabad city. Healthline. 2012;3(2):24-6.
15. Kumar N, Kanchan T, Unnikrishnan B, Rekha T, Mithra P, Kulkarni V, et al. Perceptions and Practices of Self-Medication among Medical Students in Coastal South India. PLoS One. 2013;8(8):e72247.

16. Koley M, Saha S, Ghosh A, Saha S, Ghosh S, Mondal R, et al. Self-medication practices among the undergraduate homeopathic students in West Bengal, India. Spat DD. 2014;4(2):55-62.

17. Kulkarni PK, Khan M, Chandrasekhar A. Self medication practices among urban slum dwellers in South Indian city. Int J Pharma Bio Sci. 2012;3(3):81-7.

18. Klemenc-Ketis Z, Hladnik Z, Kersnik J. Self-Medication among Healthcare and Non-Healthcare Students at University of Ljubljana, Slovenia. Med Princ Pract. 2010;19:395-401.

19. Golar SK. Use and understanding of analgesics (painkillers) by Aston university students. Biosci Horizons. 2011;4(1):71-8.

20. Sarahroodi S, Maleki-Jamshid A, Sawalha A, Mikaili P, Safaeian L. Pattern of self-medication with analgesics among Iranian University students in central Iran. J Fam Community Med. 2012;19(2):125.

21. Ibrahim NK, Alamoudi BM, Baamer WO, Al-Raddadi RM. Self-medication with analgesics among medical students and interns in King Abdulaziz University, Jeddah, Saudi Arabia. Pakistan J Med Sci. 2015;31(1):14-8.

22. O'Rourke M, Garland MR, Mccormick PA. Ease of access is a principal factor in the frequency of paracetamol overdose. Ir J Med Sci. 2002;171(3):148-50. 